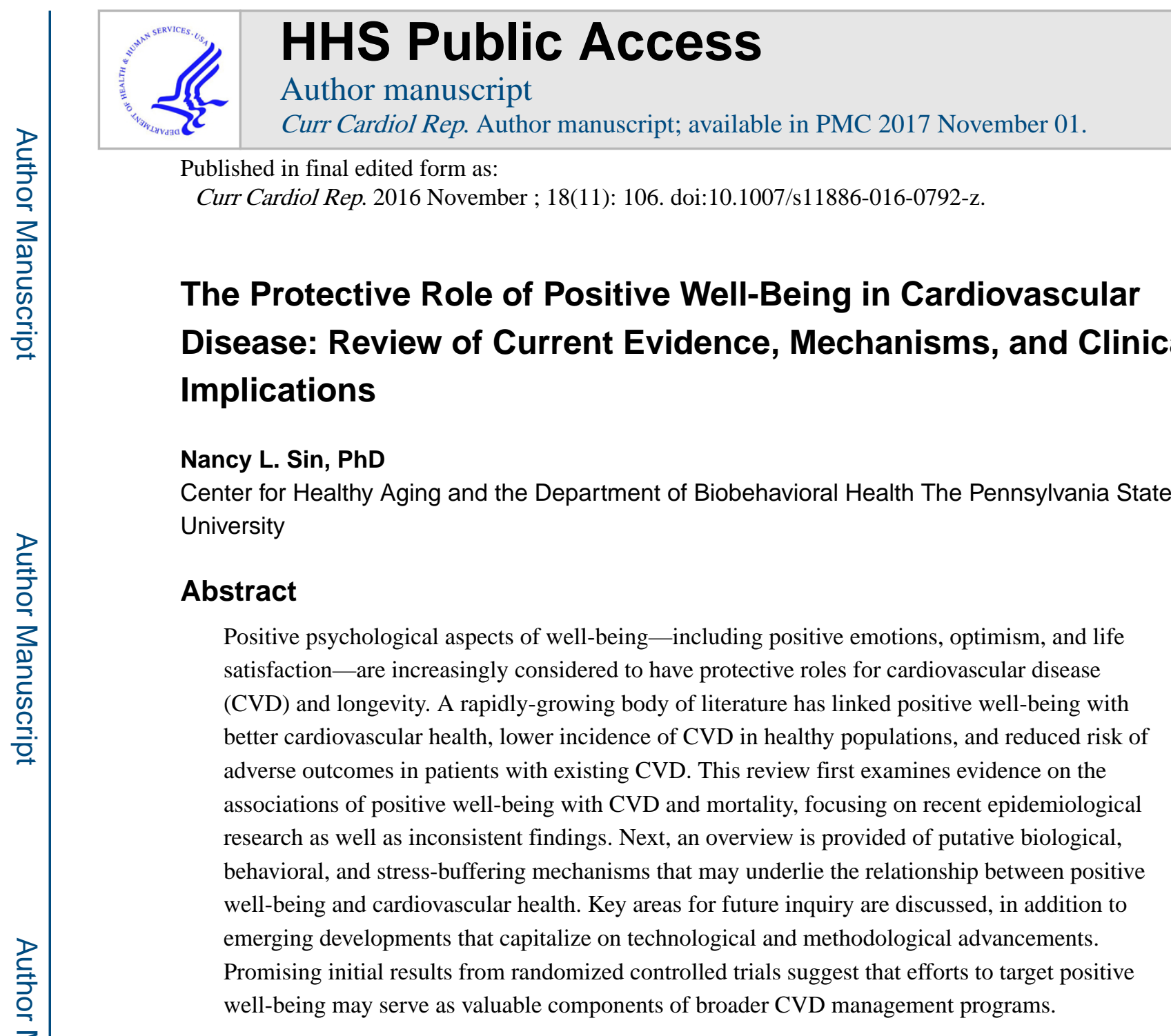

Keywords

positive affect; well-being; optimism; cardiovascular disease; mortality; health behaviors

\title{
Introduction
}

\begin{abstract}
Decades of research have documented the role of negative psychological factors-including depression, anxiety, and hostility - in the development and progression of cardiovascular disease (CVD) [1-3]. By contrast, a rapidly-growing body of work has linked positive psychological characteristics with better health and longevity [4,5], including lower levels of traditional CVD risk factors and decreased incidence of CVD [6]. Prospective investigations of patients with existing CVD have shown that greater positive well-being is associated with
\end{abstract}

\footnotetext{
Address for correspondence: Nancy L. Sin, PhD, Center for Healthy Aging, The Pennsylvania State University, 422 Biobehavioral Health Building, University Park, PA 16802, Phone: +1 (814) 865 - 4817, Fax: +1 (814) 863 - 9423, nancy.sin@ psu.edu.

Compliance with Ethics Guidelines

Human and Animal Rights and Informed Consent

This article does not contain any studies with human or animal subjects performed by any of the authors.

Conflict of Interest

Nancy L. Sin declares that she has no conflict of interest.
} 
reduced risk of secondary cardiovascular events and mortality [6,7]. As CVD remains the leading cause of death in the U.S. and worldwide [8], increasing attention is directed towards preventing CVD and promoting ideal cardiovascular health throughout the life course [9]. Positive well-being may serve as a modifiable protective factor that could reduce the burden of CVD through its potential influences on lifestyle behaviors and CVD-related biomarkers $[6,10,11]$.

The purpose of this review is to highlight the latest evidence relating positive well-being with cardiovascular outcomes, mortality, and CVD risk factors. Next, this article will provide an overview of putative biological, behavioral, and stress-buffering mechanisms. Gaps in current knowledge and areas of innovation will be examined, followed by a discussion of clinical implications. Due to the growing literature and recent developments on the topic of positive well-being and CVD, this review will primarily emphasize large-scale investigations from the past 5 years. For further reading, interested readers are advised to see other reviews on the associations of positive well-being with cardiovascular health [6], health outcomes in patients with established CVD [7], and mortality [4].

\section{What is positive well-being?}

Positive well-being is defined as the presence of favorable emotional or cognitive psychological attributes, such as positive affect (i.e., positive emotions) and optimism. Wellbeing is not simply the absence of mental illness nor is it the opposite of negative psychological constructs such as depression [12]. Although positive and negative psychological factors are inversely correlated, positive well-being often remains independently predictive of subsequent health outcomes after accounting for depression or negative affect [10]. The study of well-being has traditionally revolved around two broad approaches [13]: hedonia is characterized by happiness, pleasure attainment, and life satisfaction [14], whereas eudaimonia is a deeper form of well-being concerned with meaning and the realization of an individual's true potential (e.g., purpose in life, personal growth) [12]. Other well-being constructs, such as optimism and emotional vitality, are associated with cardiovascular outcomes but are not strictly categorized as either hedonia or eudaimonia [6]. It should be noted that positive well-being is intertwined with related psychological and social factors, such as social support, that are also important for cardiovascular health and disease management [15]. This review will include studies that examine various well-being constructs.

\section{Evidence relating positive well-being and CVD}

\section{Cardiovascular morbidity}

A number of prospective cohort studies have linked positive well-being to lower risk of incident CVD. In the Whitehall II cohort of British civil servants, nearly 8000 middle-aged participants responded to questions regarding their optimism (i.e., positive expectations for one's future), emotional vitality (i.e., active engagement with the world, emotion regulation, and overall sense of well-being), and satisfaction with various life domains (e.g., job, family). Compared to those with low levels of emotional vitality or optimism, people with moderate and high levels of vitality or optimism had approximately $20-30 \%$ reduced risk of 
incident coronary heart disease (CHD) 5 years later [16]. Greater satisfaction across life domains also predicted reduced CHD risk, particularly angina [17]. Similar results have been reported from nationally-representative U.S. samples, in which optimism predicted lower 4-year incidence of heart failure [18] and purpose in life was associated with reduced 4-year stroke risk among 6800 older adults in the Health and Retirement Study [19]. In the National Health and Nutrition Examination Survey, emotional vitality was predictive of reduced stroke risk across 16 years in over 6000 participants [20]. Furthermore, positive affect was protective against 10-year incident CHD in the Canadian Nova Scotia Health Survey [21]. Importantly, the findings of these studies persisted after accounting for negative psychological characteristics (e.g., depression, anxiety, hostility) and biological and behavioral risk factors.

Among patients with existing CVD, those with greater positive well-being tend to have reduced risk of secondary events and better health behaviors. For example, greater purpose in life predicted lower risk of myocardial infarction across 2 years in participants with CHD [22]. In addition, positive affect was associated with reduced risk of myocardial infarction and death 2 years after percutaneous coronary intervention with stent implantation, whereas depression and anxiety were not predictive of clinical outcomes [23]. Several recent investigations have examined optimism and recovery among cardiac patients. Compared to pessimists, optimists were less likely to be rehospitalized and more likely to respond to depression treatment by 8 months after coronary artery bypass graft surgery [24]. Greater optimism (but not gratitude) after acute coronary syndrome was associated with lower rates of cardiac readmissions and more physical activity 6 months later; however, optimism and gratitude were unrelated to levels of inflammation or other prognostic biomarkers [25]. In another study, optimism predicted better physical health status, reduced depressive symptoms, and better health behaviors 12 months following acute coronary syndrome [26].

\section{Mortality}

Numerous investigations have demonstrated that positive well-being is associated with longevity in people with and without CVD [4-6]. In the English Longitudinal Study of Aging, nearly 3900 older men and women rated their current feelings of positive affect 4 times over the course of a single day. Participants in the highest tertile of positive affect (aggregated across assessments) had a 35\% reduction in mortality risk across 5 years compared to those with low positive affect, adjusting for negative affect, depressed mood, demographics, and health and behavioral indicators [27]. Also, life satisfaction has been shown to predict lower mortality risk in large cohorts of older adults from Australia [28], France [29], and Germany [30], spanning approximately 7 to 22 years of follow-up. However, several studies have found that the association between life satisfaction and longevity was eliminated after accounting for other indicators of positive well-being or psychosocial resources, including positive affect [29] and beliefs about having control over one's life [31]. In addition to positive affect and life satisfaction, eudaimonic well-being may be protective for longevity [32]. To illustrate, a recent national study of U.S. adults found that people with greater purpose in life lived longer than their less-purposeful counterparts, independent of the influences of positive affect, negative affect, and positive social relationships [33]. 


\section{CVD risk factors}

It has been increasingly recognized that psychosocial and behavioral factors earlier in life can contribute to the development of CVD over the course of years to decades [9,34]. Given the paramount importance of primary prevention, the American Heart Association (AHA) has called for an improvement in "cardiovascular health" as part of the AHA 2020 Impact Goals. The concept of cardiovascular health is defined by not only the absence of clinically manifest CVD but also the simultaneous presence of 4 optimal lifestyle behaviors (nonsmoking, physical activity, healthy diet, and normal body weight) and 3 favorable biomarker levels (optimal total cholesterol, blood pressure, and fasting blood glucose without drug treatment). A cross-sectional analysis of the Multi-Ethnic Study of Atherosclerosis demonstrated a graded association between optimism and cardiovascular health scores, whereby participants in the highest quartile of optimism had $92 \%$ greater odds of ideal cardiovascular health compared to the least optimistic participants [35]. Longitudinal data from the Midlife in the United States Study revealed that life satisfaction and positive affect each predicted reduced risk for incident cardiometabolic conditions across 8-11 years, but only life satisfaction was prospectively associated with lower cardiometabolic risk scores [36]. Although studies have linked positive well-being to lower levels of individual CVD risk factors (e.g., hypertension, lipid profiles) [37,38], whether positive well-being promotes overall cardiovascular health over time is less clear.

\section{Inconsistent and null findings}

Several recent large-scale studies have reported that positive well-being-specifically, positive affect—was not predictive of incident CVD and mortality [39-43]. Furthermore, several studies on positive affect and CVD have reported significant results for some health outcomes but not others [44,45]. Notably, the Million Women Study obtained assessments of happiness, self-rated health, and health behaviors at baseline from 719,671 women in the UK and tracked them for an average of 9.6 years. The investigators concluded that happiness was not independently predictive of mortality after accounting for baseline self-rated health and behavioral factors [40]. However, it is possible that happiness has protective influences on physiological functioning and health behaviors, thereby leading to better general subjective health and reduced risk of mortality. Because health behaviors and general health are often thought to be part of the pathway linking psychological factors to mortality, researchers should be cautious about interpreting these factors as confounding variables versus potential mechanisms. Indeed, data from the Million Women Study showed that greater happiness was associated with lower risks of mortality due to CHD or to all causes, before adjustment for self-rated health. Similar patterns were found for women's reports of feeling relaxed, in control, and less stressed. These associations were attenuated to nonsignificance after including self-rated health to the models; whether self-rated health was in fact a confounder or a mediator is debatable. Future investigations would benefit from having repeated longitudinal assessments of positive well-being, biobehavioral mechanisms, and health outcomes to allow for an examination of temporal ordering and change over time. 


\section{Potential pathways linking positive well-being to CVD}

Positive well-being is thought to influence CVD by (a) promoting adaptive physiological functioning, (b) motivating better health behaviors, and (c) buffering against the detrimental effects of stress on health $[5,6,46,47]$. These 3 pathways are interrelated and not mutually exclusive. Moreover, the reversed causal direction (i.e., good health leading to positive wellbeing) is possible, as are reciprocal effects between positive well-being and health.

\section{Physiological mechanisms}

Compelling evidence suggests that trait positive affect is associated with better immune function and lower levels of inflammation [48]. In an experimental study, healthy adults were exposed by nasal drops to a cold or flu virus and monitored in quarantine [49]. Participants who had greater positive affect were more resistant to developing an upper respiratory illness and reported fewer symptoms, compared to those with less positive affect. Trait negative affect, on the other hand, was not predictive of susceptibility to colds. Similarly, trait positive affect has been linked to a greater antibody response to hepatitis B vaccination, whereas negative affect was unrelated to antibody response [50]. Crosssectional studies show that positive well-being-including positive affect, purpose in life, and positive social relations-is associated with reduced inflammation in healthy adults [5158] and in patients with heart failure [59], as well as lower in vitro production of cytokines in response to endotoxin stimulation [60]. In addition to psychological dispositions, positive activities and experiences in daily life are important for health [61]. Recent studies indicate that people who experience more daily positive events (e.g., having a pleasant conversation, spending time in nature) and who are involved in productive activities, particularly volunteering, tend to have lower levels of inflammation $[62,63]$.

The hypothalamic-pituitary-adrenal axis is considered to be a key pathway whereby stress and other psychosocial factors influence health. People with higher trait positive affect are more likely to show a steeper decrease in salivary cortisol across the day, compared to those with lower positive affect $[64,65]$. Steeper diurnal cortisol slopes, in turn, are associated with reduced cardiovascular morbidity and mortality $[66,67]$. Some evidence suggests that positive affect is also associated with a less exaggerated increase in cortisol after waking (i.e., cortisol awakening response) [65,68], as well as lower cortisol reactivity to acute laboratory stressors [69]. In addition, during moments when individuals are experiencing more positive affect—relative to their usual levels of positive affect—salivary cortisol levels are reduced [70]. However, other studies have reported no association or mixed results for positive affect and cortisol [71-73]. The complexities of assessing and analyzing cortisol [74], in addition to methodological differences (e.g., laboratory versus field research, withinversus between-person designs), make it difficult to draw conclusions regarding the role of positive well-being in diurnal cortisol patterns and cortisol reactivity to real-life stress.

Positive well-being may also have protective influences on cardiovascular function and cardiac autonomic control $[5,6]$. In a study where older adults' emotions and blood pressure were assessed every day for 60 days, daily positive emotions counteracted the influence of negative emotions on systolic blood pressure [75]. The study also found that participants with higher levels of social connectedness tended to have elevated positive emotions and 
more rapid systolic blood pressure recovery from negative emotions, suggesting that socially connected people may be more adept than less-connected individuals at mobilizing positive emotions to regulate negative experiences. In another investigation, ratings of happiness aggregated across a single day was predictive of reduced ambulatory systolic blood pressure 3 years later, as well as lower ambulatory heart rate in men, independent of sociodemographics, negative affect, and other confounding variables [76]. Yet, despite the link between trait well-being and better cardiovascular function in the long-term, state or momentary positive emotions can provoke increased cardiovascular reactivity in the shortterm $[5,77]$.

\section{Behavioral mechanisms}

People with higher positive well-being tend to have better health behaviors than those with lower well-being, possibly due to greater motivation and self-efficacy [78], as well as the ability to adjust health-relevant goals and to cope with setbacks [79]. Positive dispositionsincluding optimism, life satisfaction, and purpose in life-are associated with a range of favorable health behaviors among older and younger adults, including non-smoking, greater physical activity, better dietary patterns, and lower incidence of sleep disturbances [80-84]. For example, in a large sample of patients with CHD, higher positive affect at baseline was associated with greater physical activity, better sleep quality, more medication adherence, and non-smoking 5 years later [11]. Moreover, increases in positive affect across the 5-year period co-occurred with improvements in health behaviors. In another study, patients hospitalized for an acute coronary syndrome were interviewed in the hospital and 3 months post-discharge [85]. Qualitative analyses of the interviews revealed that exercising and eating well generated positive emotions (e.g., pride), and conversely, positive attributes (e.g., optimism) prompted patients to engage in healthy behaviors. Likewise, a study of primary care patients showed that dispositional optimism and hope were associated with greater treatment adherence [83]. The literature on positive well-being and health behaviors is mostly cross-sectional, and few investigations to date have been conducted in patients with CVD or using longitudinal data. It therefore remains unclear whether positive well-being leads to better subsequent health behaviors or vice versa.

\section{Stress-buffering effects}

A number of theoretical models have been proposed to describe the benefits of positive wellbeing in the context of stress $[46,47,86-89]$. Positive well-being is thought to have multiple salutary effects during stress, such as attenuating inflammatory and cardiovascular responses to acute stressors $[68,90,91]$, counteracting the physiological effects of negative emotions [75,92], and promoting benefit-finding and adaptive coping skills $[46,86]$. For example, people who maintain positive affect when faced with stressful situations in the laboratory [90] or in everyday life [93] tend to have lower levels of pro-inflammatory cytokines and reduced risk for mortality [94]. In a study of 564 patients with CVD, negative affect predicted increased risk of CVD-related hospitalizations and all-cause mortality across 3.4 years among patients with low positive affect [95]. Patients with high positive affect, by contrast, were protected from the adverse health consequences of negative affect. Similarly, positive well-being has been shown to buffer against the detrimental influences of other 
forms of stress or adversity, including low socioeconomic status, on physiological dysregulation $[96,97]$.

\section{Evaluation of mediational pathways}

Despite abundant research linking positive well-being to physiological processes or health behaviors that are implicated in CVD, few investigations have explicitly tested mediational pathways. To date, these investigations indicate that the association between positive wellbeing and health outcomes may be largely attributable to better health behaviors $[44,45,98,99]$. In the Heart and Soul Study of over 1000 patients with stable CHD, a number of biological markers (e.g., heart rate variability, C-reactive protein, omega-3 fatty acids) and behavioral factors (e.g., physical activity, medication nonadherence, smoking) were tested as potential mediators linking positive affect to risk of all-cause mortality across 7 years [44]. Physical activity was the most important explanatory variable, resulting in a 30\% reduction in the strength of the association between positive affect and mortality. Consistent with this finding, physical activity mediated the relationship between positive affect and subsequent mortality risk in a large sample of CHD patients from Denmark [45] and in a populationbased cohort of older adults from the Netherlands [98]. Likewise, emotional vitality predicted lower risk of incident CHD across 15 years in over 6000 participants in the National Health and Nutrition Examination Survey I [99]. Health behaviors-specifically, greater physical activity, non-smoking, and moderate alcohol use-accounted for much of this association (27\%), with metabolic factors (diabetes, cholesterol, and body mass index) accounting for $16 \%$. Yet the relationship between emotional vitality and incident CHD remained significant even after adjusting for health behaviors, metabolic factors, and other potential mediators and confounding variables, suggesting that additional pathways should be considered.

\section{Areas of innovation}

\section{Methodological advances in the study of well-being}

The most common methods for assessing positive well-being are by self-report in survey studies and by positive mood induction in laboratory studies. Psychologists have also utilized a range of other methods to capture well-being, including informant reports (i.e., surveying close friends or family), analysis of writing samples for positive affective content, and intensity of smiling in photographs (e.g., $[100,101])$. Technological advancements, social media, and big data offer innovative ways to examine population-level trends in positive well-being and CVD. A recent study analyzed psychological language use in 10s of millions of Twitter messages in relation to county-level CVD mortality across the United States [102]. Counties where residents used more words reflecting positive experiences, engagement, and optimism (e.g., wonderful, friends, opportunities) had relatively lower rates of CVD mortality, whereas language patterns reflecting negative emotions were associated with greater CVD mortality risk. Interestingly, Twitter language use predicted crosssectional CVD mortality risk better than did sociodemographics and other traditional indicators (e.g., smoking, diabetes, hypertension, obesity) at the county level, suggesting that novel approaches for capturing positive and negative psychological well-being can complement traditional methods for studying the epidemiology of CVD. 
Much of the research on positive well-being and CVD has utilized trait measures of wellbeing, in which participants are asked to rate how they generally feel. Trait measures can differ from actual experiences because they are susceptible to memory biases and judgments or beliefs about how one's life is or should be [103]. Rapidly-fluctuating phenomenaincluding emotions, thoughts, and behaviors - are perhaps best captured with repeated assessments as they unfold in daily life (e.g., using smartphones or daily Internet surveys) [104]. Because emotions and cognitions are presumed to have immediate effects on physiology, psychological experiences assessed in-the-moment may be more closely related to biomarkers than global assessments of well-being [104]. Indeed, some evidence indicates that momentary positive affect is more predictive of blood pressure, heart rate, immunity, and cortisol awakening response than trait positive affect $[68,105,106]$. Another advantage of utilizing repeated assessments in daily life is the ability to examine the temporal sequencing of events (e.g., direction of associations) and to reduce confounding by using participants as their own controls. This type of research design can reveal, for example, whether elevated positive emotions earlier in the day predict dietary choices, physical activity, and sleep behaviors later in the day, or whether good health behaviors precede upticks in positive emotions. Furthermore, repeated assessments of daily well-being can be paired with ambulatory measures of psychophysiology and with minimally-invasive methods (such as saliva and dried blood spot collection) for measuring CVD-relevant biomarkers in everyday life [107,108]. These methodological advancements arising from mobile technologies, big data, and real-time assessments can move the field towards a better understanding of the contexts and mechanisms by which positive well-being shape cardiovascular health.

\section{Fluctuations in well-being and CVD}

Positive well-being is dynamic and changing, not static. Nonetheless, too much variability may be a signal of instability or difficulty in regulating one's emotions; these fluctuations can be detrimental for mental and physical health, independent of a person's average level of well-being [109,110]. In a study of approximately 4500 Australians, participants with higher variability in life satisfaction from year to year had increased mortality risk; yet, as expected, greater overall life satisfaction (averaged across years) was protective against mortality [28]. On the other hand, variability in well-being can be adaptive when it reflects the ability to flexibly match one's emotions appropriately to situational demands [111]. The dynamic characteristics of positive well-being may have important implications for psychological adaptation and physical health, in addition to illuminating avenues for intervention.

\section{Implications for measuring well-being in clinical practice}

Considering these complexities of positive well-being, a key challenge lies in the assessment of positive well-being in clinical cardiology practice. Brief measures are commonly used in research, such as a single item about happiness [112,113], the 6-item Life Orientation TestRevised for optimism [114], and the 10-item positive affect subscale of the Positive and Negative Affect Schedule [115]. However, these measures have not been validated for clinical use in cardiac patients. Mobile health applications provide a potential tool for measuring trait psychological and social well-being, in addition to monitoring changes in 
well-being. Further work is needed to develop and optimize brief, valid, and reliable measures of positive well-being for clinical use.

\section{Clinical Implications}

Despite the well-established link between psychological factors (particularly depression) and CVD, randomized trials of traditional depression treatments in CVD patients have demonstrated only modest improvements in depressive symptoms but no effects on cardiovascular outcomes [116-118]. Thus, novel approaches for improving psychological functioning should be considered. For example, programs focusing on exercise and comprehensive lifestyle changes (e.g., stress management training combined with cardiac rehabilitation) have been shown to improve mental and physical health [119-121]. Given the evidence linking positive well-being to better health outcomes, efforts to target positive wellbeing may serve as important components of broader CVD management programs. Positive psychology interventions that aim at cultivate positive thoughts, feelings, and behaviors are effective for enhancing well-being and ameliorating depressive symptoms [122,123]. Randomized controlled trials of positive affect and self-affirmation interventions [78], in combination with patient education, have shown clinically significant increases in physical activity among patients after percutaneous coronary intervention [124] and improvements in medication adherence among hypertensive African Americans [125], compared with patient education alone. In a recent study, patients assigned to cardiac rehabilitation combined with a positive well-being program showed improvements in their emotional states and reduced hostility 8 weeks later, compared to the control group that participated in only cardiac rehabilitation [126]. Positive psychology interventions have also shown promising effects for improving biomarkers of inflammation and cortisol in a pilot trial of patients with recent coronary artery bypass graft surgery or percutaneous intervention, relative to a wait-list control group [127]. While these initial results are encouraging, large-scale and wellcontrolled studies are needed to test whether positive psychology interventions can lead to clinically significant improvements in biological, behavioral, and CVD outcomes. Moreover, the effectiveness of positive psychology interventions compared to other psychological interventions (e.g., depression treatments, stress management) for cardiac populations remains unknown.

\section{Conclusion}

By and large, people are motivated to be happy and to lead purposeful, engaged lives. Among the many functions and benefits of positive well-being [87,113], its salutary influences on cardiovascular health and longevity present opportunities for reducing the burden of CVD. Accumulating evidence from large-scale studies have demonstrated that positive well-being is protective against $\mathrm{CVD}$ risk factors, incident CVD, secondary cardiovascular events, and mortality $[4,6,7,10]$. The associations between positive wellbeing and CVD outcomes are perhaps largely mediated by better health behaviors (e.g., physical activity, sleep, diet, non-smoking, and medication adherence) among people with greater well-being $[11,80,84]$. Positive well-being is also linked to better immune, neuroendocrine, and cardiovascular functioning, in addition to reduced stress reactivity and adaptive coping skills. However, the literature has inconsistent findings and key gaps in 
knowledge, including a dearth of prospective studies on mechanistic pathways. Abundant opportunities exist to better understand the pathways and contexts underlying positive wellbeing, particularly by harnessing big data, employing ambulatory methodologies, and investigating dynamic characteristics of positive well-being. Interventions to enhance positive well-being or to sustain well-being in the face of stress may have the potential to promote favorable physiological functioning, optimal health behaviors, and downstream cardiovascular outcomes.

\section{Acknowledgments}

Nancy L. Sin was supported by National Institute on Aging grant F32AG048698.

\section{References}

Papers of particular interest, published recently, have been highlighted as:

- Of importance

•• Of major importance

1. Chida Y, Steptoe A. The Association of Anger and Hostility With Future Coronary Heart Disease: A Meta-Analytic Review of Prospective Evidence. J. Am. Coll. Cardiol. 2009; 53:936-946. [PubMed: 19281923]

2. Roest AM, Martens EJ, de Jonge P, Denollet J. Anxiety and risk of incident coronary heart disease: a meta-analysis. J. Am. Coll. Cardiol. 2010; 56:38-46. [PubMed: 20620715]

3. Whooley MA, Wong JM. Depression and cardiovascular disorders. Annu. Rev. Clin. Psychol. 2013; 9:327-354. [PubMed: 23537487]

4. Chida Y, Steptoe A. Positive psychological well-being and mortality: a quantitative review of prospective observational studies. Psychosom. Med. 2008; 70:741-756. [PubMed: 18725425]

5. Pressman SD, Cohen S. Does Positive Affect Influence Health? Psychol. Bull. 2005; 131:925-971. [PubMed: 16351329]

6. Boehm JK, Kubzansky LD. The heart's content: The association between positive psychological well-being and cardiovascular health. Psychol. Bull. 2012; 138:655-691. [PubMed: 22506752]

7. DuBois CM, Lopez OV, Beale EE, Healy BC, Boehm JK, Huffman JC. Relationships between positive psychological constructs and health outcomes in patients with cardiovascular disease: A systematic review. Int. J. Cardiol. 2015; 195:265-280. [PubMed: 26048390] This is a systematic review of prospective studies linking positive well-being with subsequent health outcomes in CVD patients. Meta-analytic results suggest that positive well-being may protect against risks for rehospitalizations and mortality.

8. Mozaffarian D, Benjamin EJ, Go AS, Arnett DK, Blaha MJ, Cushman M, et al. Heart Disease and Stroke Statistics-2016 Update: A Report From the American Heart Association. Circulation. 2016; 133:e38-e360. [PubMed: 26673558]

9. Lloyd-Jones DM, Hong Y, Labarthe D, Mozaffarian D, Appel LJ, Horn LV, et al. Defining and Setting National Goals for Cardiovascular Health Promotion and Disease Reduction: The American Heart Association's Strategic Impact Goal Through 2020 and Beyond. Circulation. 2010; 121:586613. [PubMed: 20089546]

10. DuBois CM, Beach SR, Kashdan TB, Nyer MB, Park ER, Celano CM, et al. Positive psychological attributes and cardiac outcomes: associations, mechanisms, and interventions. Psychosomatics. 2012; 53:303-318. [PubMed: 22748749]

11. Sin NL, Moskowitz JT, Whooley MA. Positive Affect and Health Behaviors Across 5 Years in Patients With Coronary Heart Disease: The Heart and Soul Study. Psychosom. Med. 2015; 77:1058-1066. [PubMed: 26428445] This is the perhaps the only longitudinal study linking positive well-being with a range of health behaviors in patients with CHD. Positive affect 
predicted physical activity, medication adherence, good sleep quality, and non-smoking 5 years later, and changes in positive affect co-occurred with changes in health behaviors.

12. Ryff CD, Singer B. The contours of positive human health. Psychol. Inq. 1998; 9:1-28.

13. Ryan RM, Deci EL. On happiness and human potentials: A review of research on hedonic and eudaimonic well-being. Annu. Rev. Psychol. 2001; 52:141-166. [PubMed: 11148302]

14. Diener E, Suh EM, Lucas RE, Smith HL. Subjective well-being: Three decades of progress. Psychol. Bull. 1999; 125:276-302.

15. Barth J, Schneider S, von Känel R. Lack of social support in the etiology and the prognosis of coronary heart disease: a systematic review and meta-analysis. Psychosom. Med. 2010; 72:229238. [PubMed: 20223926]

16. Boehm JK, Peterson C, Kivimaki M, Kubzansky L. A prospective study of positive psychological well-being and coronary heart disease. Health Psychol. 2011; 30:259-267. [PubMed: 21553969]

17. Boehm JK, Peterson C, Kivimaki M, Kubzansky LD. Heart health when life is satisfying: evidence from the Whitehall II cohort study. Eur. Heart J. 2011; 32:2672-2677. [PubMed: 21727096]

18. Kim ES, Smith J, Kubzansky LD. Prospective study of the association between dispositional optimism and incident heart failure. Circ. Heart Fail. 2014; 7:394-400. [PubMed: 24647117]

19. Kim ES, Sun JK, Park N, Peterson C. Purpose in life and reduced incidence of stroke in older adults: The Health and Retirement Study. J. Psychosom. Res. 2013; 74:427-432. [PubMed: 23597331]

20. Lambiase MJ, Kubzansky LD, Thurston RC. Positive psychological health and stroke risk: The benefits of emotional vitality. Health Psychol. 2015; 34:1043-1046. [PubMed: 25867031]

21. Davidson KW, Mostofsky E, Whang W. Don't worry, be happy: positive affect and reduced 10year incident coronary heart disease: The Canadian Nova Scotia Health Survey. Eur. Heart J. 2010; 31:1065-1070. [PubMed: 20164244]

22. Kim ES, Sun JK, Park N, Kubzansky LD, Peterson C. Purpose in life and reduced risk of myocardial infarction among older US adults with coronary heart disease: a two-year follow-up. J. Behav. Med. 2013; 36:124-133. [PubMed: 22359156]

23. Denollet J, Pedersen SS, Daemen J, De Jaegere P, Serruys PW, Van Domburg RT. Reduced positive affect (anhedonia) predicts major clinical events following implantation of coronary-artery stents. J. Intern. Med. 2008; 263:203-211. [PubMed: 18069998]

24. Tindle H, Belnap BH, Houck PR, Mazumdar S, Scheier MF, Matthews KA, et al. Optimism, response to treatment of depression, and rehospitalization after coronary artery bypass graft surgery. Psychosom. Med. 2012; 74:200-207. [PubMed: 22286847]

25. Huffman JC, Beale EE, Celano CM, Beach SR, Belcher AM, Moore SV, et al. Effects of Optimism and Gratitude on Physical Activity, Biomarkers, and Readmissions After an Acute Coronary Syndrome: The Gratitude Research in Acute Coronary Events Study. Circ. Cardiovasc. Qual. Outcomes. 2016; 9:55-63. [PubMed: 26646818]

26. Ronaldson A, Molloy GJ, Wikman A, Poole L, Kaski J-C, Steptoe A. Optimism and recovery after acute coronary syndrome: a clinical cohort study. Psychosom. Med. 2015; 77:311-318. [PubMed: $25738438]$

27. Steptoe A, Wardle J. Positive affect measured using ecological momentary assessment and survival in older men and women. Proc. Natl. Acad. Sci. 2011; 108:18244-18248. [PubMed: 22042845]

28. Boehm JK, Winning A, Segerstrom S, Kubzansky LD. Variability Modifies Life Satisfaction's Association With Mortality Risk in Older Adults. Psychol. Sci. 2015:1-8. This large-scale study of Australian adults demonstrated that high variability in life satisfaction from year to year was associated with increased mortality risk. These findings point to the importance of examining dynamic characteristics and changes in positive well-being.

29. Gana K, Broc G, Saada Y, Amieva H, Quintard B. Subjective wellbeing and longevity: Findings from a 22-year cohort study. J. Psychosom. Res. 2016; 85:28-34. [PubMed: 27212667]

30. Wiest M, Schüz B, Webster N, Wurm S. Subjective well-being and mortality revisited: Differential effects of cognitive and emotional facets of well-being on mortality. Health Psychol. 2011; 30:728-735. [PubMed: 21604881]

31. Wiest M, Schüz B, Wurm S. Life satisfaction and feeling in control: Indicators of successful aging predict mortality in old age. J. Health Psychol. 2013; 18:1199-1208. [PubMed: 23129835] 
32. Rozanski A. Behavioral cardiology: Current advances and future directions. J. Am. Coll. Cardiol. 2014; 64:100-110. [PubMed: 24998134]

33. Hill PL, Turiano NA. Purpose in life as a predictor of mortality across adulthood. Psychol. Sci. 2014; 25:1482-1486. [PubMed: 24815612]

34. Su S, Jimenez MP, Roberts CT, Loucks EB. The Role of Adverse Childhood Experiences in Cardiovascular Disease Risk: a Review with Emphasis on Plausible Mechanisms. Curr. Cardiol. Rep. 2015; 17:1-10. [PubMed: 25612925]

35. Hernandez R, Kershaw KN, Siddique J, Boehm JK, Kubzansky LD, Diez-Roux A, et al. Optimism and Cardiovascular Health: Multi-Ethnic Study of Atherosclerosis (MESA). Health Behav. Policy Rev. 2015; 2:62-73. [PubMed: 26213688]

36. Boehm JK, Chen Y, Williams DR, Ryff CD, Kubzansky LD. Subjective well-being and cardiometabolic health: An 8-11 year study of midlife adults. J. Psychosom. Res. 2016; 85:1-8. [PubMed: 27212662]

37. Boehm JK, Williams DR, Rimm EB, Ryff C, Kubzansky LD. Relation between optimism and lipids in midlife. Am. J. Cardiol. 2013; 111:1425-1431. [PubMed: 23433765]

38. Trudel-Fitzgerald C, Boehm JK, Kivimaki M, Kubzansky LD. Taking the tension out of hypertension: a prospective study of psychological well being and hypertension. J. Hypertens. 2014; 32:1222-1228. [PubMed: 24786293]

39. Freak-Poli R, Mirza SS, Franco OH, Ikram MA, Hofman A, Tiemeier H. Positive affect is not associated with incidence of cardiovascular disease: a population-based study of older persons. Prev. Med. 2015; 74:14-20. [PubMed: 25661731]

40. Liu B, Floud S, Pirie K, Green J, Peto R, Beral V, et al. Does happiness itself directly affect mortality? The prospective UK Million Women Study. Lancet. 2016; 387:874-881. [PubMed: 26684609] This widely-publicized study found that, after adjustment for self-rated health, happiness was no longer associated with reduced mortality risk.

41. Nabi H, Kivimaki M, De Vogli R, Marmot MG, Singh-Manoux A. Whitehall II Prospective Cohort Study. Positive and negative affect and risk of coronary heart disease: Whitehall II prospective cohort study. BMJ. 2008; 337:a118. [PubMed: 18595926]

42. Ortega FB, Lee D, Sui X, Kubzansky LD, Ruiz JR, Baruth M, et al. Psychological well-being, cardiorespiratory fitness, and long-term survival. Am. J. Prev. Med. 2010; 39:440-448. [PubMed: 20965381]

43. Stewart JC, Zielke DJ, Hawkins MAW, Williams DR, Carnethon MR, Knox SS, et al. Depressive Symptom Clusters and 5-Year Incidence of Coronary Artery Calcification The Coronary Artery Risk Development in Young Adults Study. Circulation. 2012; 126:410-417. [PubMed: 22711275]

44. Hoen PW, Denollet J, de Jonge P, Whooley MA. Positive affect and survival in patients with stable coronary heart disease: Findings from the Heart and Soul Study. J. Clin. Psychiatry. 2013; 74:716722. [PubMed: 23945449] This study evaluated a range of potential biological and behavioral mediators in the link between positive affect and all-cause mortality among patients with CHD. The association was largely explained by health behaviors, particularly physical activity.

45. Hoogwegt MT, Versteeg H, Hansen TB, Thygesen LC, Pedersen SS, Zwisler A-D. Exercise mediates the association between positive affect and 5-year mortality in patients with ischemic heart disease. Circ. Cardiovasc. Qual. Outcomes. 2013; 6:559-566. [PubMed: 24021694]

46. Folkman S, Moskowitz JT. Positive affect and the other side of coping. Am. Psychol. 2000; 55:647-654. [PubMed: 10892207]

47. Ong AD. Pathways Linking Positive Emotion and Health in Later Life. Curr. Dir. Psychol. Sci. 2010; 19:358-362.

48. Marsland AL, Pressman S, Cohen S. Positive affect and immune function. Psychoneuroimmunology Ed R Ader. 2007:261-279.

49. Cohen S, Alper CM, Doyle WJ, Treanor JJ, Turner RB. Positive emotional style predicts resistance to illness after experimental exposure to rhinovirus or influenza a virus. Psychosom. Med. 2006; 68:809-815. [PubMed: 17101814]

50. Marsland AL, Cohen S, Rabin BS, Manuck SB. Trait positive affect and antibody response to hepatitis B vaccination. Brain. Behav. Immun. 2006; 20:261-269. [PubMed: 16293394] 
51. Deverts DJ, Cohen S, DiLillo VG, Lewis CE, Kiefe C, Whooley M, et al. Depressive symptoms, race, and circulating C-reactive protein: the Coronary Artery Risk Development in Young Adults (CARDIA) study. Psychosom. Med. 2010; 72:734-741. [PubMed: 20668285]

52. Friedman EM, Hayney M, Love GD, Singer BH, Ryff CD. Plasma interleukin-6 and soluble IL-6 receptors are associated with psychological well-being in aging women. Health Psychol. 2007; 26:305-313. [PubMed: 17500617]

53. Friedman EM, Hayney MS, Love GD, Urry HL, Rosenkranz MA, Davidson RJ, et al. Social relationships, sleep quality, and interleukin-6 in aging women. Proc. Natl. Acad. Sci. U. S. A. 2005; 102:18757-18762. [PubMed: 16339311]

54. Friedman EM, Ryff CD. Living well with medical comorbidities: a biopsychosocial perspective. J. Gerontol. B. Psychol. Sci. Soc. Sci. 2012; 67:535-544. [PubMed: 22377799]

55. Stellar JE, John-Henderson N, Anderson CL, Gordon AM, McNeil GD, Keltner D. Positive affect and markers of inflammation: Discrete positive emotions predict lower levels of inflammatory cytokines. Emotion. 2015; 15:129-133. [PubMed: 25603133]

56. Steptoe A, O’Donnell K, Badrick E, Kumari M, Marmot M. Neuroendocrine and Inflammatory Factors Associated with Positive Affect in Healthy Men and Women The Whitehall II Study. Am. J. Epidemiol. 2008; 167:96-102. [PubMed: 17916595]

57. Sturgeon JA, Arewasikporn A, Okun MA, Davis MC, Ong AD, Zautra AJ. The Psychosocial Context of Financial Stress: Implications for Inflammation and Psychological Health. Psychosom. Med. 2016; 78:134-143. [PubMed: 26569541]

58. von Känel R, Mausbach BT, Dimsdale JE, Mills PJ, Patterson TL, Ancoli-Israel S, et al. Ways of coping and biomarkers of an increased atherothrombotic cardiovascular disease risk in elderly individuals. Cardiovasc. Psychiatry Neurol. 2012; 2012:1-9.

59. Brouwers C, Mommersteeg PMC, Nyklíček I, Pelle AJ, Westerhuis BLWJJM, Szabó BM, et al. Positive affect dimensions and their association with inflammatory biomarkers in patients with chronic heart failure. Biol. Psychol. 2013; 92:220-226. [PubMed: 23085133]

60. Prather AA, Marsland AL, Muldoon MF, Manuck SB. Positive affective style covaries with stimulated IL-6 and IL-10 production in a middle-aged community sample. Brain. Behav. Immun. 2007; 21:1033-1037. [PubMed: 17548183]

61. Pressman SD, Matthews KA, Cohen S, Martire LM, Scheier M, Baum A, et al. Association of enjoyable leisure activities with psychological and physical well-being. Psychosom. Med. 2009; 71:725. [PubMed: 19592515]

62. Kim S, Ferraro KF. Do Productive Activities Reduce Inflammation in Later Life? Multiple Roles, Frequency of Activities, and C-Reactive Protein. The Gerontologist. 2014; 54:830-839. [PubMed: 23969258]

63. Sin NL, Graham-Engeland JE, Almeida DM. Daily positive events and inflammation: Findings from the National Study of Daily Experiences. Brain. Behav. Immun. 2015; 43:130-138. [PubMed: 25102453]

64. Hoyt LT, Craske MG, Mineka S, Adam EK. Positive and negative affect and arousal: crosssectional and longitudinal associations with adolescent cortisol diurnal rhythms. Psychosom. Med. 2015; 77:392-401. [PubMed: 25905661]

65. Miller KG, Wright AGC, Peterson LM, Kamarck TW, Anderson BA, Kirschbaum C, et al. Trait positive and negative emotionality differentially associate with diurnal cortisol activity. Psychoneuroendocrinology. 2016; 68:177-185. [PubMed: 26986092]

66. Kumari M, Shipley M, Stafford M, Kivimaki M. Association of Diurnal Patterns in Salivary Cortisol with All-Cause and Cardiovascular Mortality: Findings from the Whitehall II Study. J. Clin. Endocrinol. Metab. 2011; 96:1478-1485. [PubMed: 21346074]

67. Matthews K, Schwartz J, Cohen S, Seeman T. Diurnal cortisol decline is related to coronary calcification: CARDIA study. Psychosom. Med. 2006; 68:657-661. [PubMed: 17012518]

68. Steptoe A, Gibson EL, Hamer M, Wardle J. Neuroendocrine and cardiovascular correlates of positive affect measured by ecological momentary assessment and by questionnaire. Psychoneuroendocrinology. 2007; 32:56-64. [PubMed: 17157442] 
69. Bostock S, Hamer M, Wawrzyniak AJ, Mitchell ES, Steptoe A. Positive emotional style and subjective, cardiovascular and cortisol responses to acute laboratory stress. Psychoneuroendocrinology. 2011; 36:1175-1183. [PubMed: 21398040]

70. Smyth J, Ockenfels MC, Porter L, Kirschbaum C, Hellhammer DH, Stone AA. Stressors and mood measured on a momentary basis are associated with salivary cortisol secretion. Psychoneuroendocrinology. 1998; 23:353-370. [PubMed: 9695136]

71. Adam EK, Hawkley LC, Kudielka BM, Cacioppo JT. Day-to-day dynamics of experience-cortisol associations in a population-based sample of older adults. Proc. Natl. Acad. Sci. 2006; 103:1705817063. [PubMed: 17075058]

72. Jacobs N, Myin-Germeys I, Derom C, Delespaul P, van Os J, Nicolson NA. A momentary assessment study of the relationship between affective and adrenocortical stress responses in daily life. Biol. Psychol. 2007; 74:60-66. [PubMed: 16942831]

73. Polk DE, Cohen S, Doyle WJ, Skoner DP, Kirschbaum C. State and trait affect as predictors of salivary cortisol in healthy adults. Psychoneuroendocrinology. 2005; 30:261-272. [PubMed: 15511600]

74. Adam EK, Kumari M. Assessing salivary cortisol in large-scale, epidemiological research. Psychoneuroendocrinology. 2009; 34:1423-1436. [PubMed: 19647372]

75. Ong AD, Allaire JC. Cardiovascular Intraindividual Variability in Later Life: The Influence of Social Connectedness and Positive Emotions. Psychol. Aging. 2005; 20:476-485. [PubMed: 16248706]

76. Steptoe A, Wardle J. Positive affect and biological function in everyday life. Neurobiol. Aging. 2005; 26:108-112. [PubMed: 16213629]

77. Schwerdtfeger AR, Gerteis AKS. The manifold effects of positive affect on heart rate variability in everyday life: Distinguishing within-person and between-person associations. Health Psychol. 2014 No Pagination Specified.

78. Charlson ME, Wells MT, Peterson JC, Boutin-Foster C, Ogedegbe GO, Mancuso CA, et al. Mediators and moderators of behavior change in patients with chronic cardiopulmonary disease: the impact of positive affect and self-affirmation. Transl. Behav. Med. 2014; 4:7-17. [PubMed: 24653772] This paper describes 3 randomized controlled trials in which a positive affect/selfaffirmation intervention improved health behaviors among patients with cardiopulmonary disease.

79. Rasmussen HN, Wrosch C, Scheier MF, Carver CS. Self-Regulation Processes and Health: The Importance of Optimism and Goal Adjustment. J. Pers. 2006; 74:1721-1748. [PubMed: 17083664]

80. Boehm JK, Vie LL, Kubzansky LD. The Promise of Well-Being Interventions for Improving Health Risk Behaviors. Curr. Cardiovasc. Risk Rep. 2012; 6:511-519.

81. Grant N, Wardle J, Steptoe A. The relationship between life satisfaction and health behavior: a cross-cultural analysis of young adults. Int. J. Behav. Med. 2009; 16:259-268. [PubMed: 19319695]

82. Kim ES, Hershner SD, Strecher VJ. Purpose in life and incidence of sleep disturbances. J. Behav. Med. 2015; 38:590-597. [PubMed: 25822118]

83. Nsamenang SA, Hirsch JK. Positive psychological determinants of treatment adherence among primary care patients. Prim. Health Care Res. Dev. 2015; 16:398-406. [PubMed: 25158934]

84. Steptoe A, Wright C, Kunz-Ebrecht SR, Iliffe S. Dispositional optimism and health behaviour in community-dwelling older people: associations with healthy ageing. Br. J. Health Psychol. 2006; 11:71-84. [PubMed: 16480556]

85. Huffman JC, DuBois CM, Mastromauro CA, Moore SV, Suarez L, Park ER. Positive psychological states and health behaviors in acute coronary syndrome patients: A qualitative study. J. Health Psychol. 2014

86. Bower JE, Moskowitz JT, Epel E. Is Benefit Finding Good for Your Health? Pathways Linking Positive Life Changes After Stress and Physical Health Outcomes. Curr. Dir. Psychol. Sci. 2009; 18:337-341.

87. Fredrickson BL. What good are positive emotions? Rev. Gen. Psychol. 1998; 2:300-319. [PubMed: 21850154] 
88. Hobfoll SE. Conservation of resources: A new attempt at conceptualizing stress. Am. Psychol. 1989; 44:513-524. [PubMed: 2648906]

89. Zautra AJ, Reich JW, Davis MC, Potter PT, Nicolson NA. The Role of Stressful Events in the Relationship Between Positive and Negative Affects: Evidence From Field and Experimental Studies. J. Pers. 2000; 68:927-951. [PubMed: 11001154]

90. Aschbacher K, Epel E, Wolkowitz OM, Prather AA, Puterman E, Dhabhar FS. Maintenance of a positive outlook during acute stress protects against pro-inflammatory reactivity and future depressive symptoms. Brain. Behav. Immun. 2012; 26:346-352. [PubMed: 22119400]

91. Steptoe A, Wardle J, Marmot M. Positive affect and health-related neuroendocrine, cardiovascular, and inflammatory processes. Proc. Natl. Acad. Sci. U. S. A. 2005; 102:6508-6512. [PubMed: 15840727]

92. Fredrickson BL, Mancuso RA, Branigan C, Tugade MM. The undoing effect of positive emotions. Motiv. Emot. 2000; 24:237-258. [PubMed: 21731120]

93. Sin NL, Graham-Engeland JE, Ong AD, Almeida DM. Affective reactivity to daily stressors is associated with elevated inflammation. Health Psychol. 2015; 34:1154-1165. [PubMed: 26030309]

94. Mroczek DK, Stawski RS, Turiano NA, Chan W, Almeida DM, Neupert SD, et al. Emotional reactivity and mortality: Longitudinal findings from the VA Normative Aging Study. J. Gerontol. B. Psychol. Sci. Soc. Sci. 2015; 70:398-406. [PubMed: 24170714]

95. Meyer FA, von Känel R, Saner H, Schmid J-P, Stauber S. Positive affect moderates the effect of negative affect on cardiovascular disease-related hospitalizations and all-cause mortality after cardiac rehabilitation. Eur. J. Prev. Cardiol. 2015; 22:1247-1253. [PubMed: 25208905] This is one of the only studies to examine the "buffering effect" of positive affect on subsequent health outcomes in patients with CVD. Findings showed that positive affect mitigated the influence of negative affect on CVD-related hospitalizations and all-cause mortality.

96. Morozink JA, Friedman EM, Coe CL, Ryff CD. Socioeconomic and psychosocial predictors of interleukin-6 in the MIDUS national sample. Health Psychol. 2010; 29:626. [PubMed: 20954777]

97. Zilioli S, Imami L, Slatcher RB. Life satisfaction moderates the impact of socioeconomic status on diurnal cortisol slope. Psychoneuroendocrinology. 2015; 60:91-95. [PubMed: 26142240]

98. Koopmans TA, Geleijnse JM, Zitman FG, Giltay EJ. Effects of happiness on all-cause mortality during 15 years of follow-up: The Arnhem Elderly Study. J. Happiness Stud. 2010; 11:113-124.

99. Kubzansky LD, Thurston RC. Emotional vitality and incident coronary heart disease: benefits of healthy psychological functioning. Arch. Gen. Psychiatry. 2007; 64:1393-1401. [PubMed: 18056547]

100. Pressman SD, Cohen S. Positive emotion word use and longevity in famous deceased psychologists. Health Psychol. 2012; 31:297-305. [PubMed: 21928902]

101. Abel EL, Kruger ML. Smile intensity in photographs predicts longevity. Psychol. Sci. 2010; 21:542-544. [PubMed: 20424098]

102. Eichstaedt JC, Schwartz HA, Kern ML, Park G, Labarthe DR, Merchant RM, et al. Psychological Language on Twitter Predicts County-Level Heart Disease Mortality. Psychol. Sci. 2015; 26:159169. [PubMed: 25605707] This innovative study examined language use in Twitter messages in relation to county-level CHD mortality in the United States. Counties where residents expressed more positive experiences, engagement, and optimism in their Twitter messages had relatively lower rates of CHD mortality.

103. Kahneman D, Riis J. Living, and thinking about it: Two perspectives on life. Sci. Well-Being. 2005:285-304.

104. Conner TS, Barrett LF. Trends in Ambulatory Self-Report: The Role of Momentary Experience in Psychosomatic Medicine. Psychosom. Med. 2012; 74:327-337. [PubMed: 22582330]

105. Cohen S, Doyle WJ, Turner RB, Alper CM, Skoner DP. Emotional style and susceptibility to the common cold. Psychosom. Med. 2003; 65:652-657. [PubMed: 12883117]

106. Kamarck TW, Schwartz JE, Shiffman S, Muldoon MF, Sutton-Tyrrell K, Janicki DL. Psychosocial stress and cardiovascular risk: What is the role of daily experience? J. Pers. 2005; 73:1749-1774. [PubMed: 16274452] 
107. Slavish DC, Graham-Engeland JE, Smyth JM, Engeland CG. Salivary markers of inflammation in response to acute stress. Brain. Behav. Immun. 2015; 44:253-269. [PubMed: 25205395]

108. Samuelsson LB, Hall MH, McLean S, Porter JH, Berkman L, Marino M, et al. Validation of Biomarkers of CVD Risk from Dried Blood Spots in Community-Based Research: Methodologies and Study-Specific Serum Equivalencies. Biodemography Soc. Biol. 2015; 61:285-297. [PubMed: 26652683]

109. Gruber J, Kogan A, Quoidbach J, Mauss IB. Happiness is best kept stable: Positive emotion variability is associated with poorer psychological health. Emotion. 2013; 13:1-6. [PubMed: 23163709]

110. Ong AD, Exner-Cortens D, Riffin C, Steptoe A, Zautra A, Almeida DM. Linking stable and dynamic features of positive affect to sleep. Ann. Behav. Med. 2013; 46:52-61. [PubMed: 23483378]

111. Hardy J, Segerstrom SC. Intra-individual variability and psychological flexibility: Affect and health in a National US sample. J. Res. Personal. 2016

112. Abdel-Khalek AM. Measuring happiness with a single-item scale. Soc. Behav. Personal. 2006; 34:139-150.

113. Lyubomirsky S, King L, Diener E. The Benefits of Frequent Positive Affect: Does Happiness Lead to Success? Psychol. Bull. 2005; 131:803-855. [PubMed: 16351326]

114. Scheier MF, Carver CS, Bridges MW. Distinguishing optimism from neuroticism (and trait anxiety, self-mastery, and self-esteem): a reevaluation of the Life Orientation Test. J. Pers. Soc. Psychol. 1994; 67:1063-1078. [PubMed: 7815302]

115. Watson D, Clark LA, Tellegen A. Development and validation of brief measures of positive and negative affect: the PANAS scales. J. Pers. Soc. Psychol. 1988; 54:1063-1070. [PubMed: 3397865]

116. Glassman AH, O’Connor CM, Califf RM, Swedberg K, Schwartz P, Bigger JT Jr, et al. Sertraline treatment of major depression in patients with acute MI or unstable angina. J. Am. Med. Assoc. 2002; 288:701-709.

117. O'Connor CM, Jiang W, Kuchibhatla M, Silva SG, Cuffe MS, Callwood DD, et al. Safety and efficacy of sertraline for depression in patients with heart failure: results of the SADHART-CHF (Sertraline Against Depression and Heart Disease in Chronic Heart Failure) trial. J. Am. Coll. Cardiol. 2010; 56:692-699. [PubMed: 20723799]

118. Berkman LF, Blumenthal J, Burg M, Carney RM, Catellier D, Cowan MJ, et al. Effects of treating depression and low perceived social support on clinical events after myocardial infarction: the Enhancing Recovery in Coronary Heart Disease Patients (ENRICHD) Randomized Trial. J. Am. Med. Assoc. 2003; 289:3106-3116.

119. Blumenthal JA, Sherwood A, Babyak MA, Watkins LL, Smith PJ, Hoffman BM, et al. Exercise and pharmacological treatment of depressive symptoms in patients with coronary heart disease: results from the UPBEAT (Understanding the Prognostic Benefits of Exercise and Antidepressant Therapy) study. J. Am. Coll. Cardiol. 2012; 60:1053-1063. [PubMed: 22858387]

120. Blumenthal JA, Babyak MA, O'Connor C, Keteyian S, Landzberg J, Howlett J, et al. Effects of exercise training on depressive symptoms in patients with chronic heart failure: the HF-ACTION randomized trial. J. Am. Med. Assoc. 2012; 308:465-474.

121. Blumenthal JA, Sherwood A, Smith PJ, Watkins L, Mabe S, Kraus WE, et al. Enhancing Cardiac Rehabilitation With Stress Management Training: A Randomized Clinical Efficacy Trial. Circulation. 2016 Available from: http://circ.ahajournals.org/content/early/2016/03/10/ CIRCULATIONAHA.115.018926.

122. Bolier L, Haverman M, Westerhof GJ, Riper H, Smit F, Bohlmeijer E. Positive psychology interventions: a meta-analysis of randomized controlled studies. BMC Public Health. 2013; 13:120. [PubMed: 23280303]

123. Sin NL, Lyubomirsky S. Enhancing well-being and alleviating depressive symptoms with positive psychology interventions: a practice-friendly meta-analysis. J. Clin. Psychol. 2009; 65:467-487. [PubMed: 19301241] 
124. Peterson JC, Charlson ME, Hoffman Z, Wells MT, Wong S-C, Hollenberg JP, et al. A randomized controlled trial of positive-affect induction to promote physical activity after percutaneous coronary intervention. Arch. Intern. Med. 2012; 172:329-336. [PubMed: 22269589]

125. Ogedegbe GO, Boutin-Foster C, Wells MT, Allegrante JP, Isen AM, Jobe JB, et al. A randomized controlled trial of positive-affect intervention and medication adherence in hypertensive African Americans. Arch. Intern. Med. 2012; 172:322-326. [PubMed: 22269592]

126. Sanjuán P, Montalbetti T, Pérez-García AM, Bermúdez J, Arranz H, Castro A. A Randomised Trial of a Positive Intervention to Promote Well-Being in Cardiac Patients. Appl. Psychol. Health Well-Being. 2016; 8:64-84. [PubMed: 26876425]

127. Nikrahan GR, Laferton JA, Asgari K, Kalantari M, Abedi MR, Etesampour A, et al. Effects of Positive Psychology Interventions on Risk Biomarkers in Coronary Patients: A Randomized, Wait-List Controlled Pilot Trial. Psychosomatics. 2016; 57:359-368. [PubMed: 27129358] This exploratory trial tested strategies to improve positive well-being in cardiac patients. The study presents initial evidence suggesting that positive psychology interventions may be effective for improving CVD risk biomarkers. 